Engineering

Elsevier Editorial System(tm) for Ocean

Manuscript Draft

Manuscript Number:

Title: Analytical Performance Assessment of a Novel Active Mooring System for Load Reduction in Marine Energy Converters

Article Type: Full length article

Keywords: Marine renewable energy; mooring systems; wave energy; tidal energy

Corresponding Author: Dr. Jamie F Luxmoore, Ph.D., MSc., MEng.

Corresponding Author's Institution: University of Exeter

First Author: Jamie F Luxmoore, Ph.D., MSc., MEng.

Order of Authors: Jamie F Luxmoore, Ph.D., MSc., MEng.; Simon Grey; David Newsam; Lars Johanning

Abstract: Reliability and storm survival of Marine Energy Converters are critical to their commercial development and deployment. The Intelligent Active Mooring System (IAMS) is a novel device intended to minimise extreme and fatigue loading in mooring lines through a non-linear loadextension curve that is variable in operation to adjust to the prevailing metocean conditions. A static model of IAMS, validated by physical model tests at the Dynamic Marine Component test facility at the University of Exeter, is used in a dynamic simulation of the performance of IAMS as part of the mooring system of the South West Mooring Test Facility buoy. A $10 \mathrm{~m}$ length of IAMS can reduce the rms line tension in normal operating conditions by up to 21\% and the peak line tension in storm conditions by up to 21\% when compared to braided nylon mooring lines. Peak line tension reductions of over 50\% can be achieved if a longer IAMS unit is used. The resulting mooring system can be optimised to give load reductions in a wide range of metocean conditions; while variable pre-tension could be used for tidal range compensation or to ease access for installation and maintenance.

Suggested Reviewers: Lars Bergdahl

Lars.Bergdahldchalmers.se

Extensive experience and recent publications in the field.

Claudio Bittencourt Ferreira

Business development director wave and tidal, DNV-GL

claudio.bittencourt. ferreiraddnvgl.com

Experienced industry perspective

Stephen Banfield

Managing Director, Tension Technology International

banfieldetensiontech.com

Extensive experience in the design and use of novel mooring systems and fibre rope systems 

College of Engineering, Mathematics and Physical Sciences

University of Exeter, Cornwall Campus

Penryn, TR10 9EZ, UK

$6^{\text {th }}$ April 2016

Dear Editors,

I enclose a paper submission for your consideration, which I feel is appropriate for publication in Ocean Engineering.

The outcomes relate primarily to the mooring of floating Marine Renewable Energy (MRE) devices, although the results could be applicable to any moored device. The work is based on physical and numerical modelling of a recently developed active mooring system component.

The results show that the ability to alter the load-extension relationship of a mooring line in operation can lead to significant reductions in the peak and fatigue loads on the mooring system and hence on the moored device. The results show that the novel system gives a clear reduction in peak and rms loads on a representative device and that the benefits can be enhanced by altering the loadextension characteristics in response to the metocean conditions. As such I believe that the work can contribute to reducing the cost of energy from MRE devices by improving reliability and storm survival.

Many thanks for considering this article for publication,

Yours faithfully,

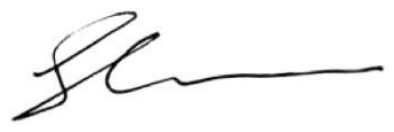

Jamie Luxmoore

University of Exeter 
- Novel mooring system that can be optimised to suit the metocean conditions

- Active control of the line stiffness results in significantly reduced peak loads

- Peak load reductions of over $50 \%$ have been simulated in storm conditions

- Variable pre-tension for tidal compensation or access for maintenance 
1

2

3

8

\title{
Analytical Performance Assessment of a Novel Active Mooring System for Load Reduction in Marine Energy Converters
}

\author{
Jamie F. Luxmoore ${ }^{\mathrm{a}, *}$, Simon Grey ${ }^{\mathrm{b}}$, David Newsam ${ }^{\mathrm{c}}$, Lars Johanning ${ }^{\mathrm{a}}$ \\ ${ }^{a}$ College of Engineering, Mathematics and Physical Sciences, University of Exeter, Penryn \\ Campus, Penryn, Cornwall, TR10 9EZ, UK \\ ${ }^{b}$ AWS Ocean Energy Ltd, Findhorn House, Dochfour Business Centre, Dochgarroch, \\ Inverness, IV3 $8 G Y$, UK \\ ${ }^{c}$ Teqniqa Systems Ltd, 78 York St, London W1H 1DP, UK
}

\begin{abstract}
Reliability and storm survival of Marine Energy Converters are critical to their commercial development and deployment. The Intelligent Active Mooring System (IAMS) is a novel device intended to minimise extreme and fatigue loading in mooring lines through a non-linear load-extension curve that is variable in operation to adjust to the prevailing metocean conditions. A static model of IAMS, validated by physical model tests at the Dynamic Marine Component test facility at the University of Exeter, is used in a dynamic simulation of the performance of IAMS as part of the mooring system of the South West Mooring Test Facility buoy. A $10 \mathrm{~m}$ length of IAMS can reduce the rms line tension in normal operating conditions by up to $21 \%$ and the peak line tension in storm conditions by up to $21 \%$ when compared to braided nylon mooring lines. Peak line tension reductions of over $50 \%$ can be achieved if a longer IAMS unit is used. The resulting mooring system can be optimised to give load reductions in a wide range of metocean conditions; while variable pre-tension could be used for tidal range compensation or to ease access for installation and maintenance. Keywords: Marine renewable energy, mooring systems, wave energy, tidal energy,

\footnotetext{
* Corresponding author

Email address: j.f.luxmoore@exeter.ac.uk (Jamie F. Luxmoore)
}

Preprint submitted to Ocean Engineering

April 6, 2016
\end{abstract}




\section{Introduction}

Reliability and storm survival of Marine Energy Converters (MECs) is critical to their commercial development and deployment (Thies et al. 2011). Mooring systems can significantly alter both extreme and fatigue loading in moored 5 wave and tidal stream energy converters and so drive both reliability and device survival. Mooring systems can also affect the wave energy extraction efficiency of Wave Energy Converters (WEC) (Zanuttigh et al., 2013, Johanning et al., 2007).

The requirements for a floating MEC mooring system are to provide high minimum breaking load (MBL) and good reliability and position keeping in extreme conditions while still having sufficient compliance to reduce the peak and operating loads on the device (Gordelier et al. 2014). The usual solution is to employ fibre ropes, but a small number of alternative designs have been proposed recently which offer significant advantages over fibre ropes, primar-

15 ily through having a stiffness characteristic which increases with increasing line extension. For example the TfI Mooring Tether (Thies et al., 2014) has an elastomeric element which gives a soft response in normal operation and a separate stiff compressive element to withstand storm loads. The Seaflex system (Bengtsson and Ekström, 2010) uses elastomeric elements with a rope as backup

20 in the event of over-elongation. The Exeter Tether (Gordelier et al. 2014) is a hollow braided fibre rope with an elastomeric core - the tension load is carried by the rope while the core controls the extension by resisting the reduction in diameter as the rope extends.

The performance assessment presented here is based on a novel mooring 25 system referred to as the Intelligent Active Mooring System (IAMS) which combines user controlled axial stiffness and damping with a high MBL. The IAMS device has a load-extension curve such that the stiffness increases with increasing axial extension. The shape and steepness of the load-extension curve is variable in operation to adjust to the prevailing metocean conditions. This 
30 allows a much wider range of response characteristics than would otherwise be available. The initial aim of the novel mooring system is to minimise fatigue loading on the device and mooring system in normal operating conditions, while still providing adequate position keeping and reduced device and mooring loads in storm conditions. The MBL of the device is independent of the operating

35 axial stiffness curve chosen.

The technology is designed to significantly reduce the cost of mooring wave, tidal and floating wind installations through mooring load control and the subsequent reduction of structural loads on the floating device and the mooring system components. In the special case of a Wave Energy Converter (WEC),

40 the stiffness and damping could potentially be tuned to enhance the motion of the device, thus increasing the yield. The ability to reduce the pre-tension (by reducing the accumulator pressure) could be used to allow easy access to a MEC for servicing and installation. The variable pre-tension could also be used for tidal range compensation or even to artificially submerge a device for storm 45 survival.

This paper describes the physical scale model and the accompanying analytical model of IAMS as they relate to the performance assessment. A case study is then presented for model validation and the remaining sections comprise the dynamic performance model design and results, followed by a discussion and 50 concluding remarks.

\section{IAMS model and test approach}

The IAMS design is based around a hollow braided rope which supports all the lengthwise loads and a flexible water filled bladder inside the hollow braid which resists reductions in the braid diameter through hydraulic pressure.

${ }_{55}$ As the rope extends, the diameter of the hollow braid decreases until the rope strands finally lock together at around 17 degrees braid angle; any further extension beyond this point is due to the extension of the rope strands. Braid angle is defined as half the included angle between two crossing strands. A detailed view 
of the braid fibres is shown in figure 1. An accumulator is attached by hydraulic

${ }_{60}$ pipe to the bladder outlet so the load-extension properties of the whole system can be varied by changing the accumulator air volume and pressure.

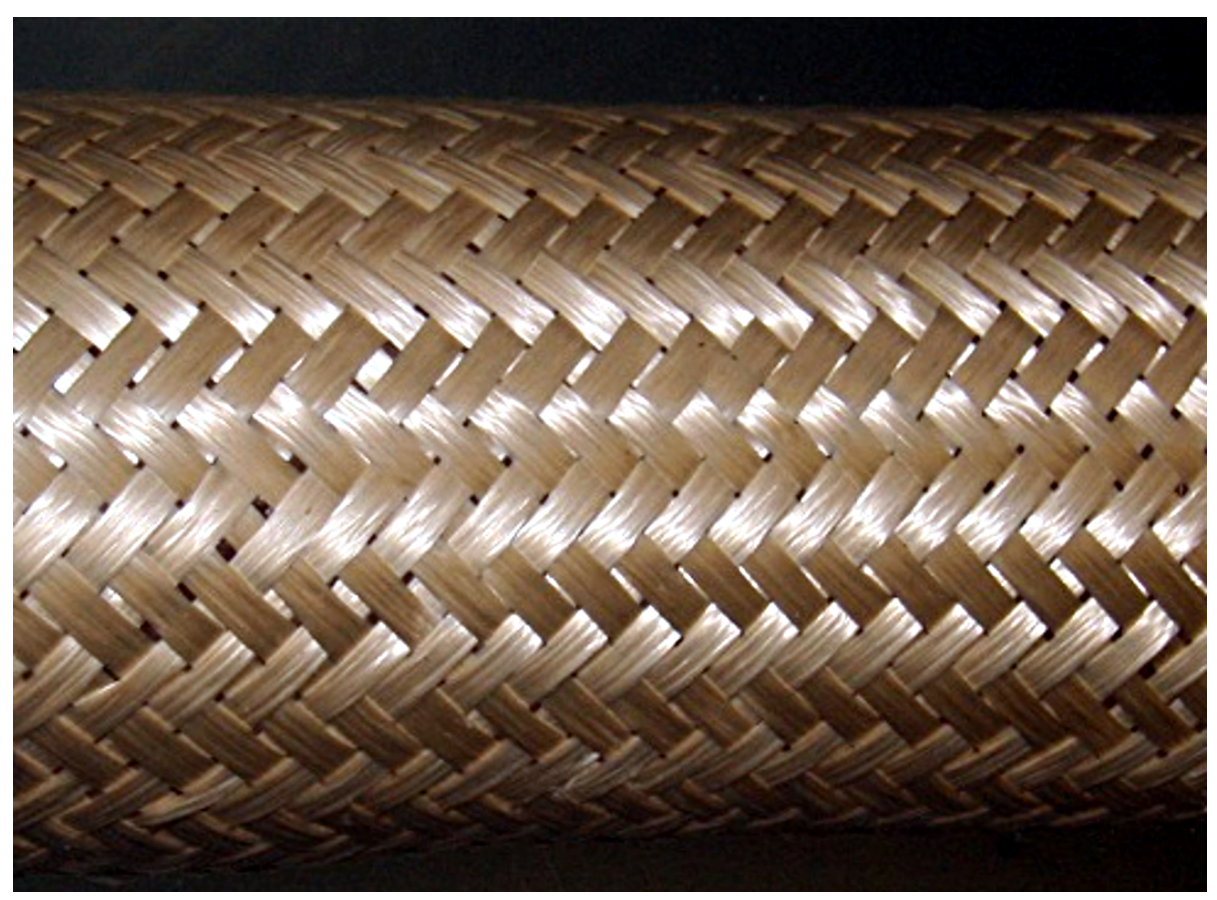

Figure 1: Detailed view of the 32 strand hollow braided Vectran rope. The individual strands are arranged so they lie nearly flat around the circumference of the water filled bladder.

\subsection{Physical scale model}

A physical model was constructed by Teqniqa Systems Ltd. at reduced scale (or for smaller applications) and was tested by the University of Exeter at the ${ }_{65}$ Dynamic Marine Component (DMaC) test facility in Falmouth docks. A full dynamic performance assessment was carried out and will be reported in future publications. The results presented in this paper concern only the semi-static tests carried out to calibrate the numerical and analytical models. Tension and position are recorded through the DMaC control system (NI Compact RIO)

70 at $250 \mathrm{kHz}$ and $120 \mathrm{kHz}$ respectively (for full details of DMaC capabilities see 
Johanning et al. (2011)). Figure 2 shows the IAMS physical model installed in $\mathrm{DMaC}$.

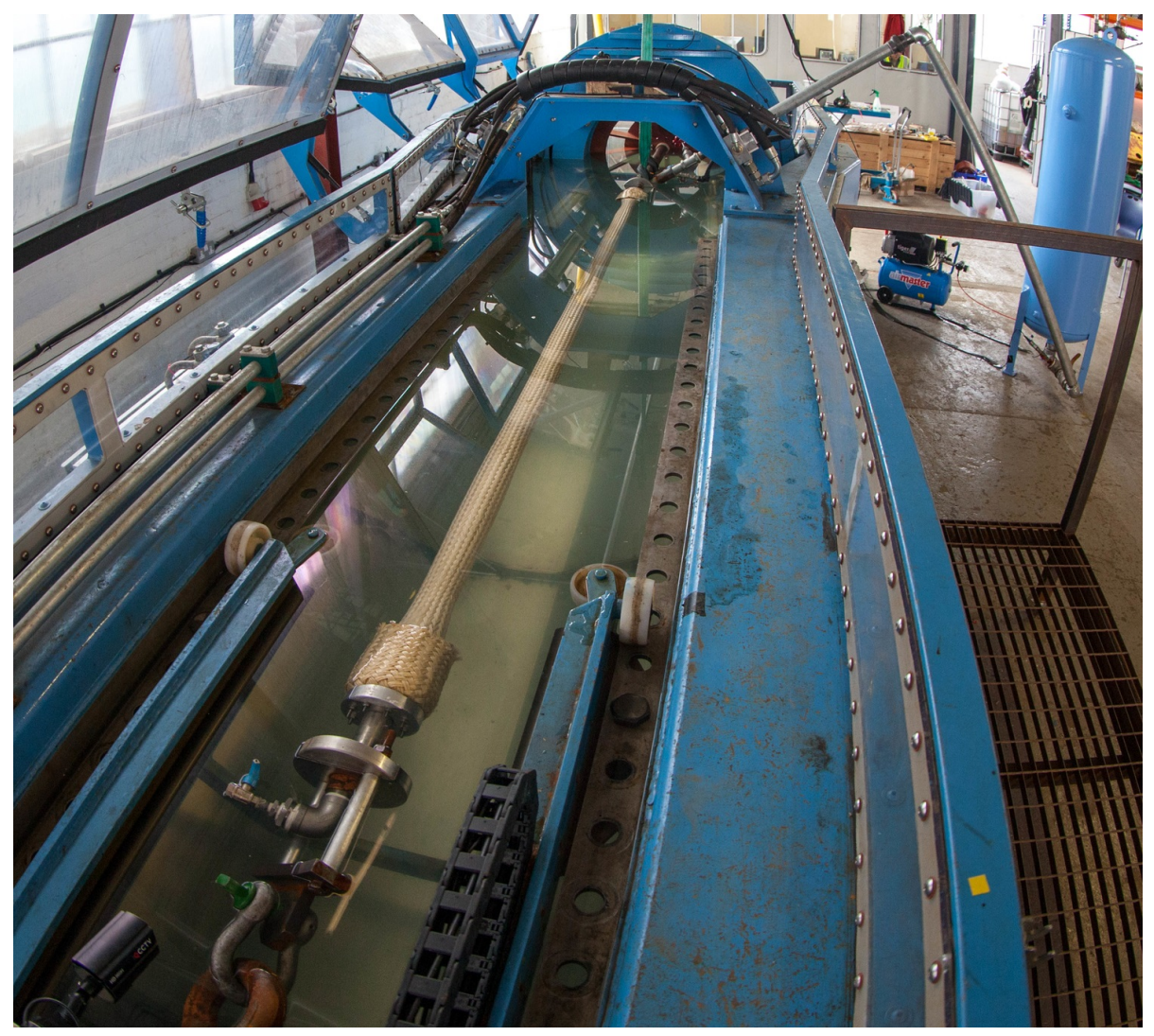

Figure 2: IAMS installed in DMaC

The pressure supply system used in the physical model tests is not representative of the proposed final design, rather it was designed for ease of installation 75 in the test rig. A schematic of the pressure supply system is shown in figure 3 The braid outlet USB pressure transducer records at $10 \mathrm{~Hz}$, while the USB pressure and temperature transducers on the accumulator record at 2.5 Hz. Emergency pressure relief valves were fitted (but not used). The main constriction in the pipework was a globe valve which caused significant pressure

so drop, but the results presented here concern only semi-static tests (period $>300$ seconds) and so are unaffected by the pressure drop. 


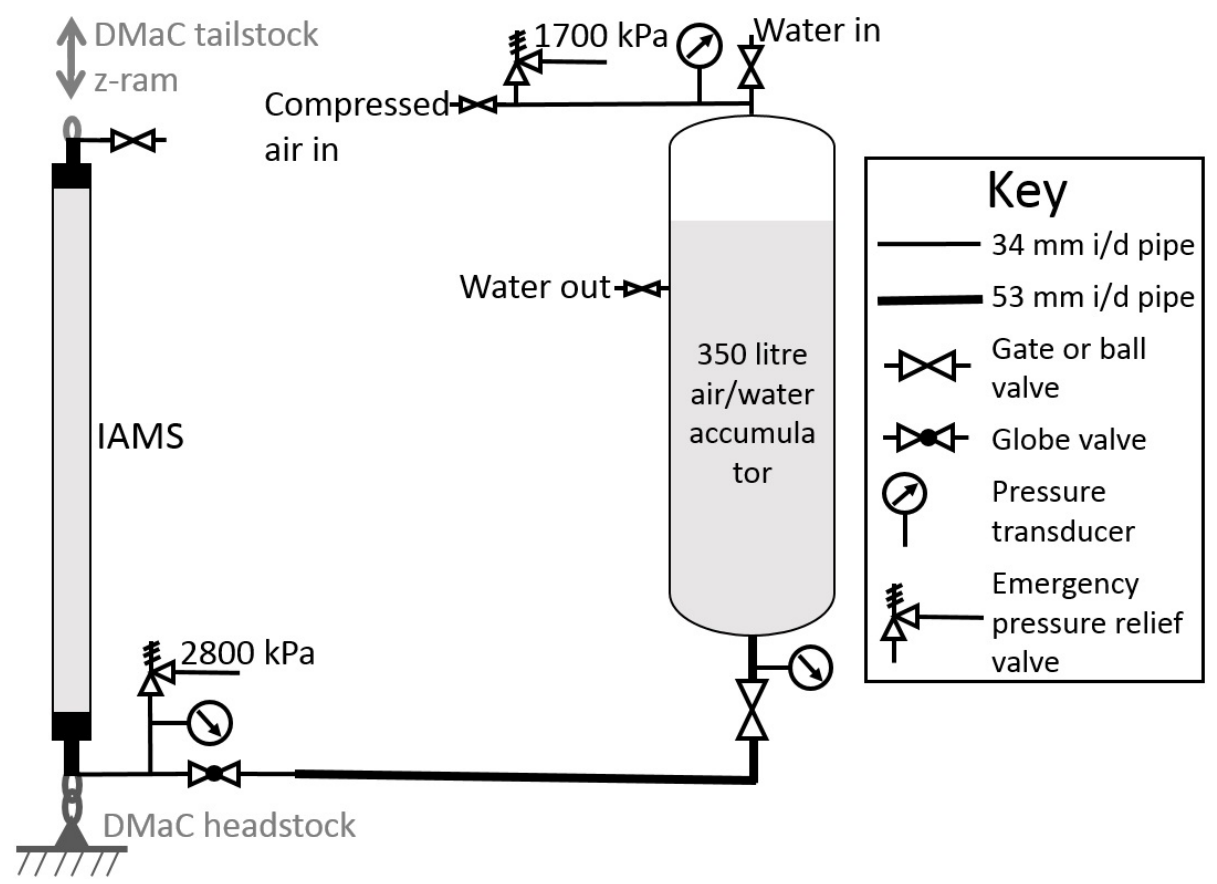

Figure 3: Pressure supply system for physical model test at DMaC

\subsection{Static model}

The performance of IAMS can be approximated using a simplified analytical model of the load-extension relationship based on the internal pressure and the

85 accumulator gas volume. The braid angle $\alpha$ can be calculated as:

$$
\alpha=\arccos \left(\frac{L_{0}+z}{L_{F}}\right)
$$

where $z$ is the elongation of IAMS, $L_{0}$ is the hollow braid length at $0 \%$ extension and $L_{F}$ is the helical length of the braid fibres (equal to the theoretical braid length at $\alpha=0)$. The cross-sectional area $A$ of the hollow braided rope section is then:

$$
A=\pi r_{0}^{2}\left(\frac{\sin \alpha}{\sin \alpha_{0}}\right)
$$

90 where $r_{0}$ is the hollow braid radius at $0 \%$ extension and $\alpha_{0}$ is the braid angle at $0 \%$ extension. The tension $T$ on the end fixings of IAMS as a result of the 
the internal pressure $P$ is then:

$$
T=P A\left(\frac{2}{\tan ^{2} \alpha}-1\right)
$$

The initial volume $V_{0}$ and pressure $P_{0}$ of the air in the top of the accumulator are set manually in the physical scale model IAMS. In the static model

95

the internal pressure $P_{1}$ at time $t_{1}$ in IAMS is calculated assuming adiabatic compression and zero loss in the pipework system from $P_{1}=P_{0}\left(V_{0} / V_{1}\right)^{\gamma}$ where $\gamma=1.4$ for air and $V_{1}$ is the volume of air in the accumulator at time $t_{1}$, calculated from $V_{0}$ less the volume of water displaced from IAMS.

This static model does not take in to account the friction between the braid fibres or between the braid and the bladder or the tension due to the bladder material. The effects of these simplifications are investigated by reference to a scaled physical model described below.

\subsection{Static model validation}

The initial internal volume of the braid and the displaced volume with extension was measured for several different fixed pressures to calibrate the analytical model. After calibration the static model gives an excellent prediction of the displaced volume ( $R^{2}=0.9998$, mean of the residuals is -0.01 litres $)$. The load prediction however shows some structural differences between the prediction and the measurements (Mean $R^{2}=0.9981$ but the mean of the residuals is $-0.54 \mathrm{kN}$ for the three tests shown in figure 44. Tests 1 and 2 shown in figure 4 are with an initial accumulator air volume of 75.0 litres while test 3 has an air volume of 28.6 litres. The start pressures are $85 \mathrm{kPa}, 200 \mathrm{kPa}$ and $37 \mathrm{kPa}$ respectively. These tests were conducted with the full system so the pressure increases as the braid extends. For each measurement, the length of the test section was increased by $10 \mathrm{~cm}$ over 10 seconds and then held steady for 30 seconds, with the values plotted representing the mean of the final 10 seconds of hold.

The difference between the predicted load and the measured load is primarily due to the friction between the braid strands. As each helical braid strand crosses over another the fibres deviate up or down from a circular helix by half 
the thickness of the strand they are crossing over. Friction is caused at the intersection of the strands. At short braid extensions this will tend to limit the reduction in length due to the internal pressure (effectively the fibres lock together at around 50 degrees braid angle), so the recorded loads will be lower than the (pressure only) analytical model will predict. At long braid extensions

Figure 4: Load predictions plotted against measured data from move and hold tests for three pressure/volume combinations

the inter-strand friction will increase the force required to extend the braid, resulting in higher loads for a given extension than would be predicted by the static model. The data presented in figure 4 agrees with this hypothesis as the load predictions are above the measurements for low extension and below the measurements at high extension.

A further set of semi-static tests were completed with the braid extension increasing from nominal $0 \%$ to $33 \%$ extension (from 45 degrees to 21 degrees braid angle) and back again in a sine wave over 5 minutes. Four initial pressure and accumulator air volume combinations were tested as shown in table 1. The results are shown in figure 5 together with the static model predictions. On 
the higher line while the retracting portion is the lower line forming a typical hysteresis loop.

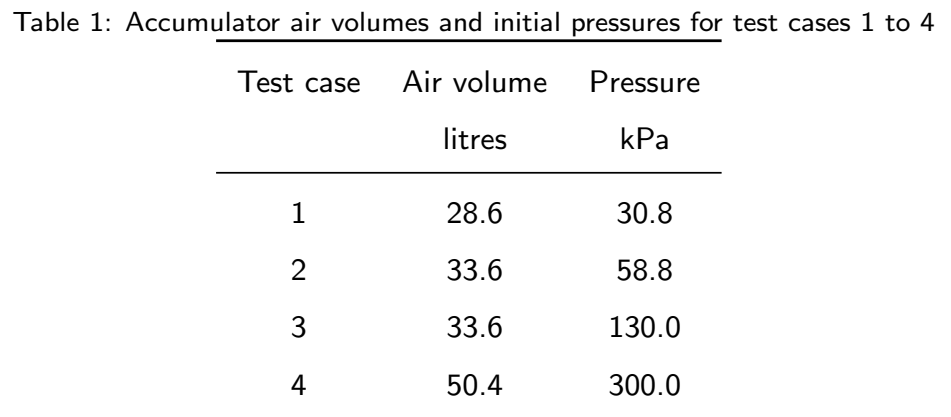
(Orcina Ltd, 2015) version 9.8a. A case study was completed for model validation using data from the South West Moorings Test Facility (SWMTF) buoy (Johanning et al. 2008), which is an instrumented ocean buoy designed to provide data to reduce the uncertainties in reliability and cost estimates for moored 155 cause of the differences between the analytical model and the physical model. Other factors not included in the static model are the friction between the braid and the bladder and the tension due to the elasticity of the bladder material. Both these additional factors are small - the bladder is separated from the braid by two layers of polyethylene plastic sheeting which has very low frictional properties when wet and the bladder itself has a Young's modulus of $6 \mathrm{~N} / \mathrm{mm}^{2}$, so a $30 \%$ extension of the bladder alone would require approximately $0.6 \mathrm{kN}$. Overall the static model is able to predict the stiffness characteristics of IAMS well, but the hysteresis characteristics are not included.

\section{IAMS mooring case study}

The dynamic models described in this paper have been run using Orcaflex WECs. The SWMTF buoy is instrumented with load cells on the mooring lines,

The static model predictions are consistently near the middle of the hysteresis loop for these four test cases. The braid-on-braid friction is the principle 
kinematic acceleration sensors, wind and current sensors, a GPS unit, temperature and humidity sensors and a heading compass. There is also a bottom mounted Acoustic Doppler Current Profiler (ADCP) which can derive a directional surface wave profile and vertical wave and current profiles along each of SWMTF. Values of $C_{D}$ and $C_{M}$ were selected from guidance in Wilson et al. (2003) as $C_{D}=1.2$ and $C_{M}=1.5$. Unit damping moments of $5 \mathrm{kN} \cdot \mathrm{m} /(\mathrm{rad} / \mathrm{s})$ normally and $1 \mathrm{kN} . \mathrm{m} /(\mathrm{rad} / \mathrm{s})$ axially were selected by sensitivity study comparing the model motion to the motion of the real buoy. There is some uncertainty

Validation data was selected from the 9th October 2010, when a typical sea state $\left(H_{s}=2.44 \mathrm{~m}\right)$ resulted in a high snatch load of $54 \mathrm{kN}$ with all instruments functioning correctly. The wave frequency and directional spectra at the selected

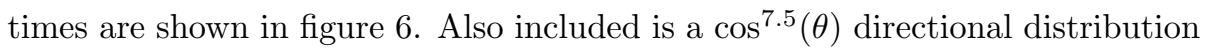
as it was necessary to approximate the directional distribution to a $\cos ^{S}(\theta)$ function in Orcaflex (the frequency spectrum could be input directly as shown). The wave direction is such that $85.4 \%$ of the rms energy absorbed by the mooring lines is absorbed by one line alone - line 3 , resulting in very high loads on this line.

The Orcaflex model uses a composite 6 degree of freedom buoy to represent surrounding the actual achieved position of the anchors for the SWMTF buoy, the positions used in this study are based on the estimated positions given in Harnois et al. (2012), as shown in figure 7 .

Results of the validation study are shown in figure 8 and table 2 with the motion relative to the peak wave direction (i.e. surge is the fore/aft motion along the $097^{\circ}$ line). The standard deviation of the position excursion is used to compare the scale of the excursions between the numerical model and the SWMTF buoy. A comparison of the standard deviation of the bulk angular velocity of the buoy is also shown. The standard deviation of the buoy surge is too high in the Orcaflex model by $63 \%$, but the heave and sway are very 185 well modelled and the bulk angular velocity is $26 \%$ lower in the Orcaflex model compared to the measured SWMTF buoy data. 
Table 2: Standard deviations of position translation and angular velocity and root mean square values of line tensions for Orcaflex model and SWMTF buoy

\begin{tabular}{lccccccc}
\hline & \multicolumn{4}{c}{ Standard deviations } & \multicolumn{3}{c}{ Root mean squares } \\
& $\begin{array}{c}\text { Surge } \\
\mathrm{m}\end{array}$ & $\begin{array}{c}\text { Sway } \\
\mathrm{m}\end{array}$ & $\begin{array}{c}\text { Heave } \\
\mathrm{m}\end{array}$ & $\begin{array}{c}\text { Angular vel. } \\
\mathrm{rad} / \mathrm{s}\end{array}$ & $\begin{array}{c}\text { Line 1 } \\
\mathrm{kN}\end{array}$ & $\begin{array}{c}\text { Line 2 } \\
\mathrm{kN}\end{array}$ & $\begin{array}{c}\text { Line 3 } \\
\mathrm{kN}\end{array}$ \\
\hline SWMTF & 0.47 & 0.40 & 0.55 & 0.31 & 2.37 & 4.86 & 8.82 \\
Orcaflex & 0.77 & 0.41 & 0.59 & 0.23 & 4.06 & 6.25 & 8.78 \\
\hline Difference & $63 \%$ & $0 \%$ & $7 \%$ & $-26 \%$ & $71 \%$ & $29 \%$ & $-1 \%$ \\
\hline
\end{tabular}

For the line tension the root mean square values (rms) are used to compare the numerical model to the SWMTF buoy as the mean values are more important than the deviation from the mean. The modelled rms of the line tension is very close to the measured value for the up-wave line (line 3) with a tension weighted mean for all three lines $19 \%$ above the measured value. The line tensions are well matched in the frequency domain between the model and the SWMTF buoy. The line tension peak frequencies are marginally higher in Orcaflex and the high frequency response is also slightly elevated compared to the measured data. Overall the Orcaflex model is able to reproduce the main motion and line tension characteristics of the SWMTF buoy well.

\section{Dynamic model study}

There are two main categories of mooring system design used in floating WECs, catenary or taut moored systems. Taut moorings have one or several lines and catenary systems have at least three lines with or without auxiliary surface buoys or lazy wave systems (Weller et al. 2013). As validation data is available for a three leg catenary system, this paper will focus on a three leg catenary system and a three leg taut moored system as shown in figure 9 .

The catenary system is identical to the system used in the validation study except where the IAMS device is substituted in to replace a section of the mooring lines. The lines are composed of $5 \mathrm{~m}$ of $32 \mathrm{~mm}$ studlink chain from the 
anchors and then $36 \mathrm{~m}$ of $24 \mathrm{~mm}$ studless chain, $20 \mathrm{~m}$ of $44 \mathrm{~mm}$ nylon Superline and finally $1 \mathrm{~m}$ of $32 \mathrm{~mm}$ studlink chain attached to the buoy. The taut moored system uses a shallow line slope $\left(60^{\circ}\right.$ off vertical) in order to maximise the line length to allow for the large tidal range. A $5 \mathrm{~m}$ length of chain with a $-1 \mathrm{Te}$ float at the junction holds $46 \mathrm{~m}$ of $44 \mathrm{~mm}$ nylon Superline off the seabed. The top end is identical to the catenary moored system.

Two sea states are considered, the sea state used for the validation study and a 100 year extreme sea state calculated by fitting a generalised extreme value distribution (see figure 10 to the wave height data available from the ADCP at the SWMTF site (method detailed in Luxmoore (2014)). This extrapolation gives a significant wave height of $H_{S_{100}}=6.51 \mathrm{~m}$. Wave steepness in extreme seas is generally in the range $1 / 20$ to $1 / 16$ (Health and Safety Executive, 2002), so assuming a steepness of $1 / 18$ gives a zero up-crossing period of $T_{Z}=8.17 \mathrm{~s}$.

The IAMS device has a variable load-extension curve - the stiffness and damping characteristics can be altered based on the prevailing metocean conditions. The aim at this stage is to minimise loading on the device and mooring system in normal operating conditions, while still providing adequate position keeping and reduced device and mooring loads in storm conditions. The load extension curve is varied by changing the volume of air in the accumulator and the pressure of that air. Four air volume / initial pressure combinations were used in the dynamic model study as detailed in figure 11 and table 3.

Table 3: Accumulator air volumes and initial pressures for configurations $A$ to $D$

\begin{tabular}{ccc} 
Configuration & $\begin{array}{c}\text { Air volume } \\
\mathrm{m}^{3}\end{array}$ & $\begin{array}{c}\text { Pressure } \\
\mathrm{kPa}\end{array}$ \\
\hline $\mathrm{A}$ & 0.72 & 158 \\
$\mathrm{~B}$ & 2.62 & 1198 \\
$\mathrm{C}$ & 0.85 & 89 \\
$\mathrm{D}$ & 2.62 & 278 \\
\hline
\end{tabular}

The prototype IAMS tested at DMaC has a nominal $120 \mathrm{~mm}$ diameter, 
while the version used for the dynamic modelling is considerably larger (305 mm diameter) and has been modelled up to higher pressures. The assumed MBL has also been increased consistent with the larger diameter end plates. A $10 \mathrm{~m}$ section of IAMS was substituted into the mooring system used in the validation study (replacing $10 \mathrm{~m}$ of the total $20 \mathrm{~m}$ of nylon Superline). The results are compared against the validation configuration (using $20 \mathrm{~m}$ of $44 \mathrm{~mm}$ nominal diameter braided nylon Superline from Bridon Ropes) and a configuration using $20 \mathrm{~m}$ of $27 \mathrm{~mm}$ nominal diameter 6 strand wire rope with wire core in place of the nylon rope. The wire rope was chosen to match the MBL of the nylon rope and designed using the line wizard in Orcaflex described in Orcina Ltd (2015).

\subsection{Dynamic model results}

The Orcaflex dynamic model was run for both the taut and the catenary mooring designs described above for all four IAMS configurations and for the nylon and wire mooring lines. For the taut system with a wire rope the buoy was submerged at high tide with no waves, so this configuration is considered unsuitable and is not discussed further. The simulations were run for 512 seconds using both the typical sea state and the extreme sea state. A short snapshot of the effects of mooring line composition for the catenary system is shown graphically in figures 12 and 13

Figures 12 and 13 provide a reference to understand the main effects of the different mooring line types. The nylon Superline provides a significantly reduced peak load compared to the wire rope while the maximum excursion is increased. The line tension for the wire rope includes some high frequency oscillations, caused by the very stiff lines coming taut. The high frequency oscillations are not present for the nylon lines or the nylon plus IAMS lines. The IAMS device can in this case be seen to provide a further load reduction and a further increase in excursion compared to the nylon only lines. These results however are only for 30 seconds of data. Figure 14 presents a timeaveraged version of the results of all the simulations.

In figure 14 the standard deviation of the buoy motion in all three directions 
has been averaged to give a measure of the relative magnitude of the total buoy movement. This has been plotted against the root mean square (rms) of the line tension for all three lines. There is a clear trend of decreasing rms line tension with increasing the magnitude of the buoy excursion. The error bars are small as the values are averaged over 60 to 80 waves.

Figure 15 shows the peak line tension for all three lines plotted against the maximum displacement of the buoy from it's starting position. Note that the SWMTF buoy was modelled as a 6-D Buoy in Orcaflex so the second order wave drift is not included (this is only available for Vessels in Orcaflex 9.8a) the hydrodynamic forces on a 6-D Buoy are calculated using Morison's equation in Orcaflex. There is a trend of decreasing peak line tension with increasing maximum buoy excursion for nearly all configurations tested. The error bars are large on these points as they are based on a single data point each - whichever wave resulted in the largest loads on the lines. This may not be the same wave in all cases and the buoy position just prior to the large wave will effect the response during the wave.

\subsection{Effects of varying IAMS stiffness}

Figure 16 shows the rms line tension for line three only (the line with the highest loads) plotted against the mean standard deviation of the buoy excursion. Of the four IAMS configurations, configuration B gives the highest rms line tension in all cases and configuration $\mathrm{C}$ gives the lowest loads in all cases.

For the catenary mooring system configuration $\mathrm{C}$ gives a reduction in rms line tension of $9 \%$ at $H_{s}=2.44 \mathrm{~m}$ and a reduction of $14 \%$ at $H_{s}=6.51 \mathrm{~m}$ compared to the braided nylon Superline alone. The increase in mean buoy excursion is $13 \%$ for both sea states. For the taut moored system with IAMS in configuration $\mathrm{C}$ the reduction in $\mathrm{rms}$ line tension is $21 \%$ at $H_{s}=2.44 \mathrm{~m}$ and $18 \%$ at $H_{s}=6.51 \mathrm{~m}$ compared to the nylon Superline. The increase in mean buoy excursion is $10 \%$ at $H_{s}=2.44 \mathrm{~m}$ and $21 \%$ at $H_{s}=6.51 \mathrm{~m}$.

Figure 17 shows the peak line tension for line 3 only plotted against the maximum buoy excursion. The estimated error bars are large as these data are 
based on a single maximum line tension value occurring once in the dataset. For the catenary system the reduction in the central estimate of the peak line tension is between $14 \%$ and $21 \%$ for the extreme sea state compared to the braided nylon Superline alone. The differences among the configurations is well within the error bars. For the taut moored system the reduction in the central estimate of the peak line tension is between $11 \%$ and $21 \%$ for the extreme sea state compared the braided nylon Superline alone. Again the differences among the configurations is within the error bars. For both the taut moored system and the catenary system IAMS configuration B gives a reduced maximum buoy excursion in an extreme sea state compared to the other IAMS configurations the maximum excursion is similar in magnitude to that of the nylon Superline alone but with a reduced peak line tension.

\subsection{Effects of varying IAMS length}

The length of the IAMS device has a significant impact on the properties of the overall system. Simulations were re-run using configuration A only with an IAMS unit $26 \mathrm{~m}$ long in the catenary system and $46 \mathrm{~m}$ long in the taut moored 305 system (in both cases these are the maximum lengths that can be accommodated in each system without risk of the IAMS unit coming into contact with the seabed). For the catenary system the rms line tension in normal operating conditions decreased further to a total of $18 \%$ reduction compared to the nylon Superline only configuration, while in extreme conditions a $57 \%$ reduction in peak line tension was achieved compared to the nylon Superline only configuration. Maximum buoy excursion was $13.8 \mathrm{~m}$ in extreme conditions. For the taut moored system (with $46 \mathrm{~m}$ of IAMS) the rms line tension in normal operating conditions decreased to a total of $23 \%$ reduction compared to the nylon Superline only configuration, while in extreme conditions a $52 \%$ reduction in peak line tension was achieved compared to the nylon Superline only configuration. Maximum horizontal buoy excursion was $14.5 \mathrm{~m}$ in extreme conditions. 


\section{Discussion}

The results of the semi-static physical model tests show that the friction between the braid fibres causes hysteresis in the IAMS load-extension curve, 320 giving a higher tension when the line is extending than when it is retracting. This may be significant in the mooring system performance, especially as it is likely that at higher frequencies there will be some additional hysteresis from the fluid flow to and from the accumulator. The hysteresis is equivalent to damping in the mooring system and will tend to reduce the motion of the buoy when the

325 line is extending and decrease the restoring force when retracting compared to a line with no damping. This source of motion damping is not included in the Orcaflex model as axial line hysteresis cannot currently be included in the model. There is however a similar source of motion damping caused by the fluid drag on the line due to the off-axis motion of the line as the catenary shape straightens and of course the lifting of the chain off the seabed causes a similar effect. These two sources of hysteresis are included in the Orcaflex model. A possible future improvement to the dynamic model might be to increase modelled crosssectional area of IAMS or the normal direction hydrodynamic drag coefficient (without changing any other properties) to simulate the increased hysteresis.

The results of the dynamic model study confirm the already well understood relationship between mooring line compliance and line tension in waves - generally the stiffer the mooring line the higher the peak and rms line tensions. This is not however true for all the results, notably in extreme storm conditions for the catenary system design when the wire rope gives lower rms and peak loads than the nylon Superline. This is likely due to the higher compliance of the nylon rope allowing the buoy to travel faster with the large waves resulting in a high load to arrest the motion.

In normal operating conditions the mooring line design should primarily aim to reduce the rms loading on the device to reduce fatigue. The exception to this is for a Wave Energy Converter (WEC) when it may be desirable to increase to motion of the device to increase the power output. The maximum 
excursion or peak loading are unlikely to be significant compared to the peak loading and excursion in extreme storm conditions. The shape of the IAMS load-extension curve depends primarily on the volume of air in the accumulator

350 - larger volumes result in a straighter characteristic while smaller volumes give a more exponential characteristic. The steepness of the IAMS load-extension curve is related to the start pressure - higher start pressures give a steeper curve. In normal operating conditions then the IAMS configurations with lower initial pressures $\mathrm{A}$ and $\mathrm{C}$, in particular $\mathrm{C}$, clearly offer a significant benefit over the traditional moorings and the other IAMS configurations, reducing the rms load on line three by $9 \%$ to $21 \%$ compared to braided nylon mooring lines depending on the mooring system layout.

In extreme operating conditions the mooring line design should primarily aim to reduce the peak loading on the device, but the maximum device excursion may also be significant in a tightly packed array of MECs. Comparing two configurations with the same accumulator air volume (B and D) but with very different initial pressures $(\mathrm{B}=1198 \mathrm{kPa} ; \mathrm{D}=278 \mathrm{kPa})$ shows that increasing the pressure reduces the maximum buoy excursion considerably, but has little effect on the peak load in extreme conditions. Comparing two configurations with relatively similar initial pressures (A and D), but with very different accumulator air volumes $\left(A=0.72 \mathrm{~m}^{3} ; \mathrm{D}=2.62 \mathrm{~m}^{3}\right)$ shows that there is a significant decrease in peak line tension with decreasing pressure but less of an effect on the maximum excursion. In extreme storm conditions then, configuration B stands out as providing significantly reduced peak line tension compared to the 370 Nylon rope ( $11 \%$ to $18 \%$ depending on the mooring system layout), but with little increase in maximum buoy excursion.

The reduction in both the rms line tension and the peak line tension is related to the length of the IAMS unit deployed, so greater reductions in the line tensions could be achieved by deploying units of more than $10 \mathrm{~m}$ length. 375 Peak load reductions of over $50 \%$ have been simulated in extreme conditions for both the taut and the catenary moored systems. There is an accompanying loss of position keeping ability, but the maximum excursions remain below 15 
$\mathrm{m}$ horizontally in a mooring system with a footprint radius of $50 \mathrm{~m}$.

The IAMS device can offer a significantly reduced peak and rms loading on a floating MEC. The most important characteristic of IAMS is that the system can be adjusted in operation to suit the prevailing metocean conditions. The compliance can be increased to attain low device loading during normal operating conditions and then can be decreased in storm conditions to maintain position keeping while still maintaining device loading below that obtainable using a braided nylon line. For the buoy and metocean conditions simulated here, configuration $\mathrm{C}$ would likely be best for the normal operating conditions, while configuration B would be best in the extreme storm conditions. Again, the exception to this would be if the buoy were to represent a WEC reliant on the device motion to induce power generation; in which case the ideal configuration in normal operating conditions would be determined by the natural frequency of the device.

\section{Conclusions}

The Intelligent Active Mooring System (IAMS) is a novel device intended to reduce the wave derived loads on floating MECs and their foundations. The work reported here is based around a fully dynamic simulation of the South West Mooring Test Facility (SWMTF) with IAMS in several configurations substituted in to the mooring lines. The Orcaflex dynamic model has been validated against data collected at SWMTF in Falmouth bay. Overall the Orcaflex model is able to simulate the main motion and line tension characteristics of the SWMTF buoy well.

A static mechanical model of the predicted performance of IAMS itself has been validated against physical scale model tests conducted at the Dynamic Marine Component (DMaC) test facility. The static model is a simplification of IAMS, as hysteresis is not included, but the overall stiffness characteristics are well predicted.

The dynamic modelling carried out here shows that the modelled IAMS de- 
vice can provide significant reductions in the line tension in a mooring system for a typical small MEC when compared to both wire moorings and braided nylon moorings. Reductions in line tension are related to the length of the IAMS Teqniqa Systems Ltd. and the University of Exeter. The project was funded in part by the Technology Strategy Board (now Innovate UK) grant number 101970.

\section{References}

${ }_{425}$ Bengtsson, N., Ekström, V., 2010. Increase life cycle and decrease cost for navigation buoys. Technical Report. Seaflex Buoy mooring system.

Gordelier, T., Parish, D., Johanning, L., Thies, P.R., 2014. A novel mooring tether for highly dynamic offshore applications; mitigating peak and fatigue loads via selectable axial stiffness, in: Proc. 4th Int. Conf. Ocean Energy,

Harnois, V., Parish, D., Johanning, L., 2012. Physical measurement of a slow drag of a drag embedment anchor during sea trials, in: Int. Conf. Ocean Energy, pp. 1-6. 
Health and Safety Executive, 2002. Offshore installations: Guidance on design, construction and certifcation: Environmental considerations. Technical Report. Offshore Technology Report 2001/010.

Johanning, L., Smith, G.H., Wolfram, J., 2007. Measurements of static and dynamic mooring line damping and their importance for floating WEC devices. Ocean Eng. 34, 1918-1934. doi $10.1016 / \mathrm{j}$. oceaneng.2007.04.002.

Johanning, L., Spargo, A., Parish, D., 2008. Large scale mooring test facility A technical note, in: Proc. 2nd Int. Conf. Ocean Energy.

Johanning, L., Thies, P.R., Parish, D., Smith, G.H., 2011. Offshore reliability approach for floating renewable energy devices, in: ASME 2011 30th Int. Conf. Ocean. offshore Arct. Eng., American Society of Mechanical Engineers. pp. 579-588.

Luxmoore, J.F., 2014. Experimental Studies of Extreme Waves and Waveinduced Loads on Wind Turbine Support Structures in Intermediate Depth Water. Ph.D. thesis. Lancaster University.

Orcina Ltd, 2015. Oracflex Version 9.8a Help Documentation. URL: http: //www .orcina.com/SoftwareProducts/OrcaFlex/Documentation/Help/

Thies, P.R., Johanning, L., McEvoy, P., 2014. A novel mooring tether for peak load mitigation: Initial performance and service simulation testing. Int. J. Mar. Energy 7, 43-56. doi 10.1016/j.ijome.2014.06.001

Thies, P.R., Johanning, L., Smith, G.H., 2011. Towards component reliability 455

testing for marine energy converters. Ocean Eng. 38, 360-370. doi 10.1016/ j.oceaneng.2010.11.011.

Weller, S., Johanning, L., Davies, P., 2013. Best practice report - mooring of floating marine renewable energy devices. Technical Report. MERiFIC Deliverable report 3.5.3. 
${ }_{460}$ Wilson, J., Muga, B., Reese, L., 2003. Dynamics of Offshore Structures. John Wiley \& Sons.

Zanuttigh, B., Angelelli, E., Kofoed, J.P., 2013. Effects of mooring systems on the performance of a wave activated body energy converter. Renew. Energy 57, 422-431. doi $10.1016 /$ j.renene.2013.02.006. 

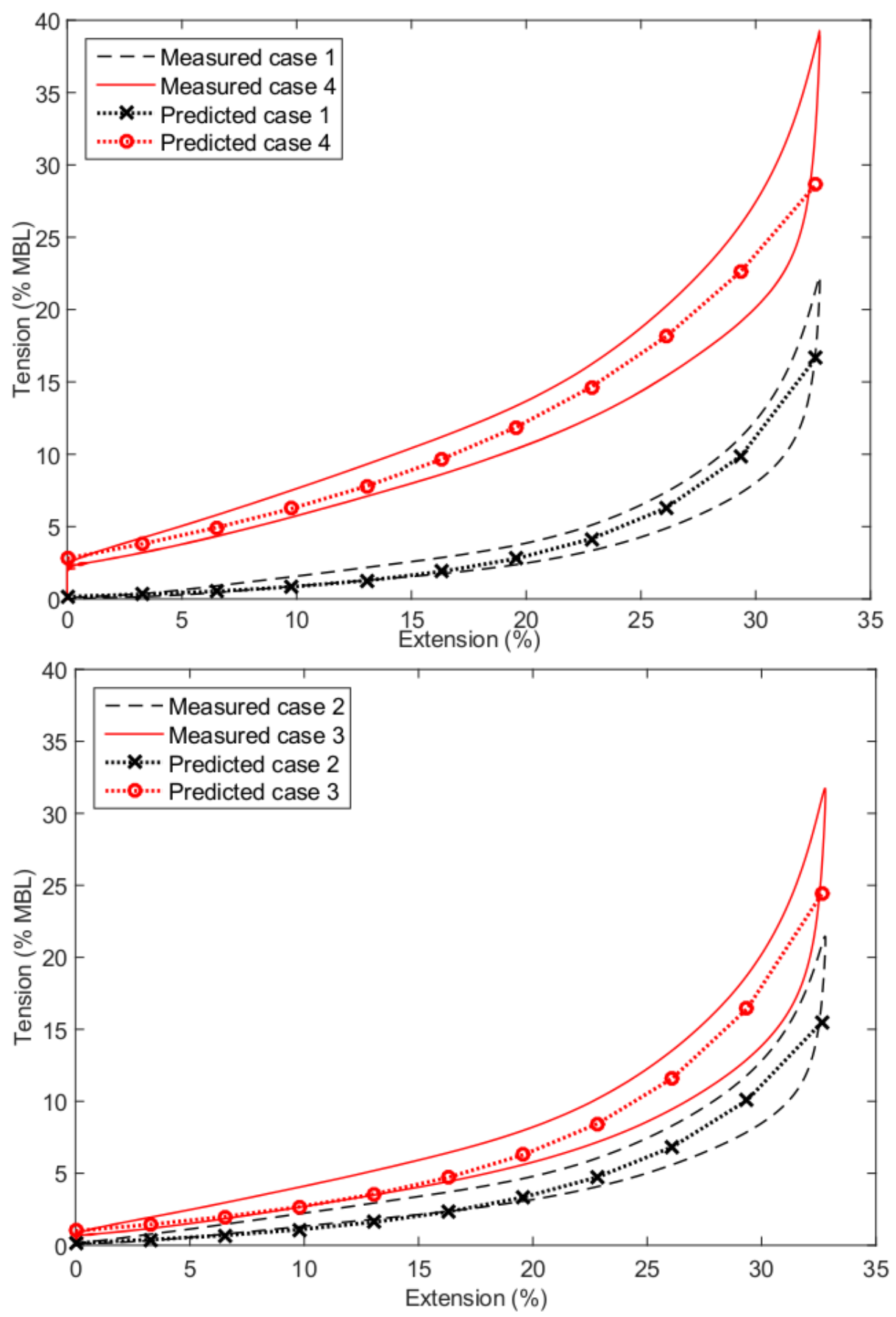

Figure 5: Measured versus predicted load-extension curves for test cases 1 to 4 

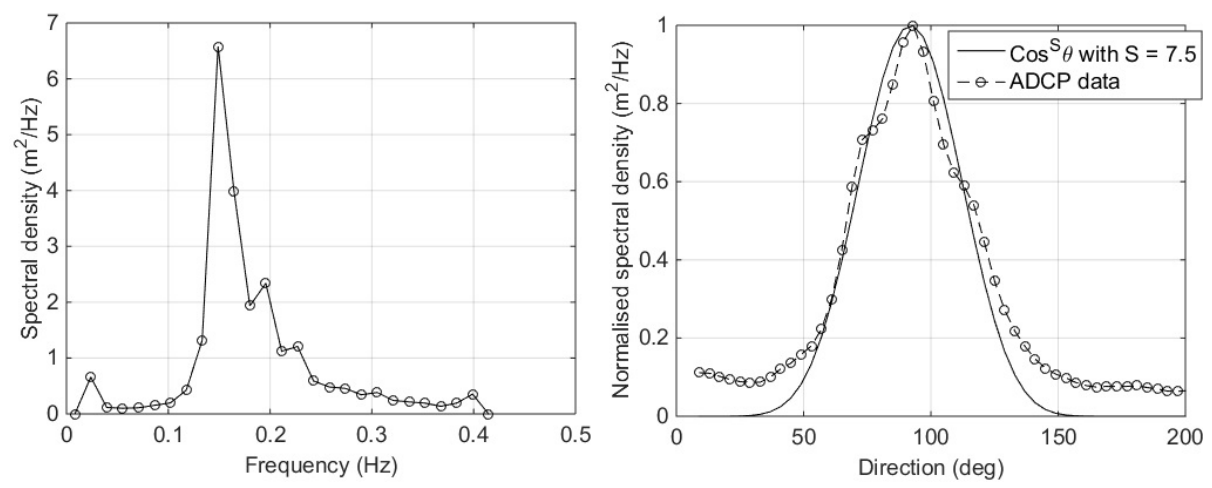

Figure 6: Wave conditions for validation test case from ADCP data. A $\cos ^{7.5}(\theta)$ directional distribution is shown for reference.

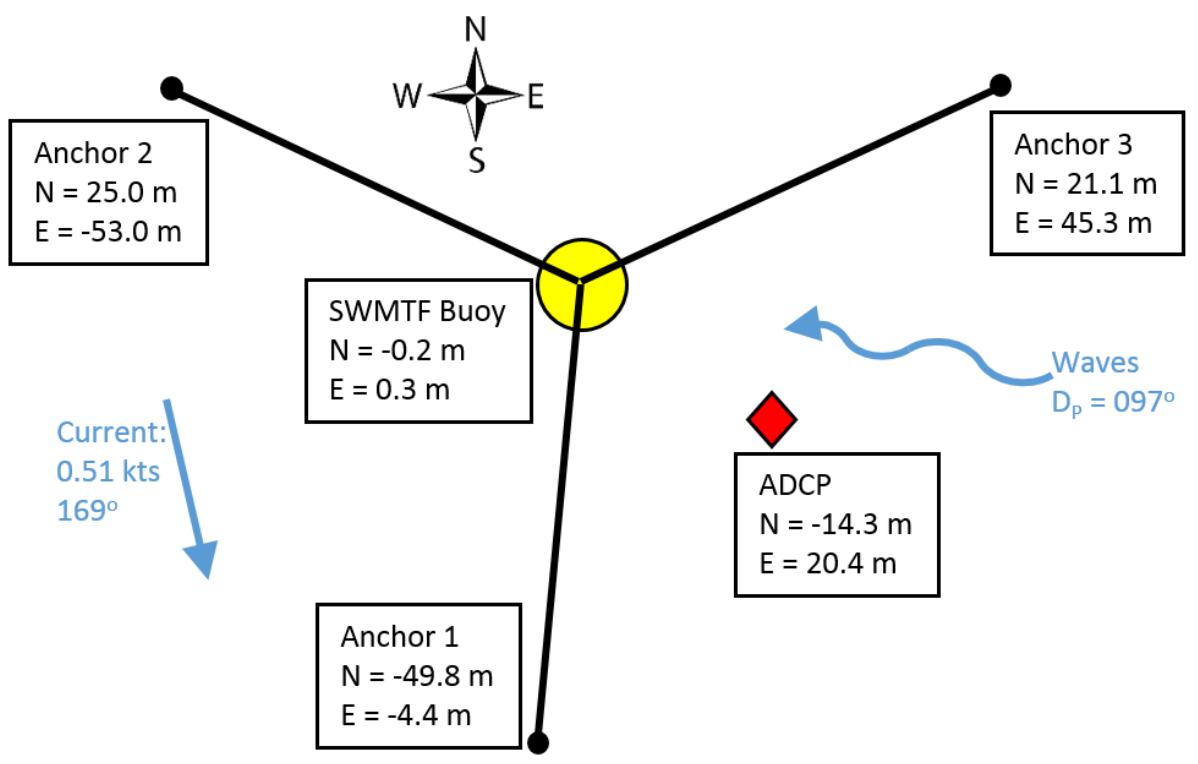

Figure 7: Anchor positions used for Orcaflex model validation. The estimated ADCP position is also shown for reference. 


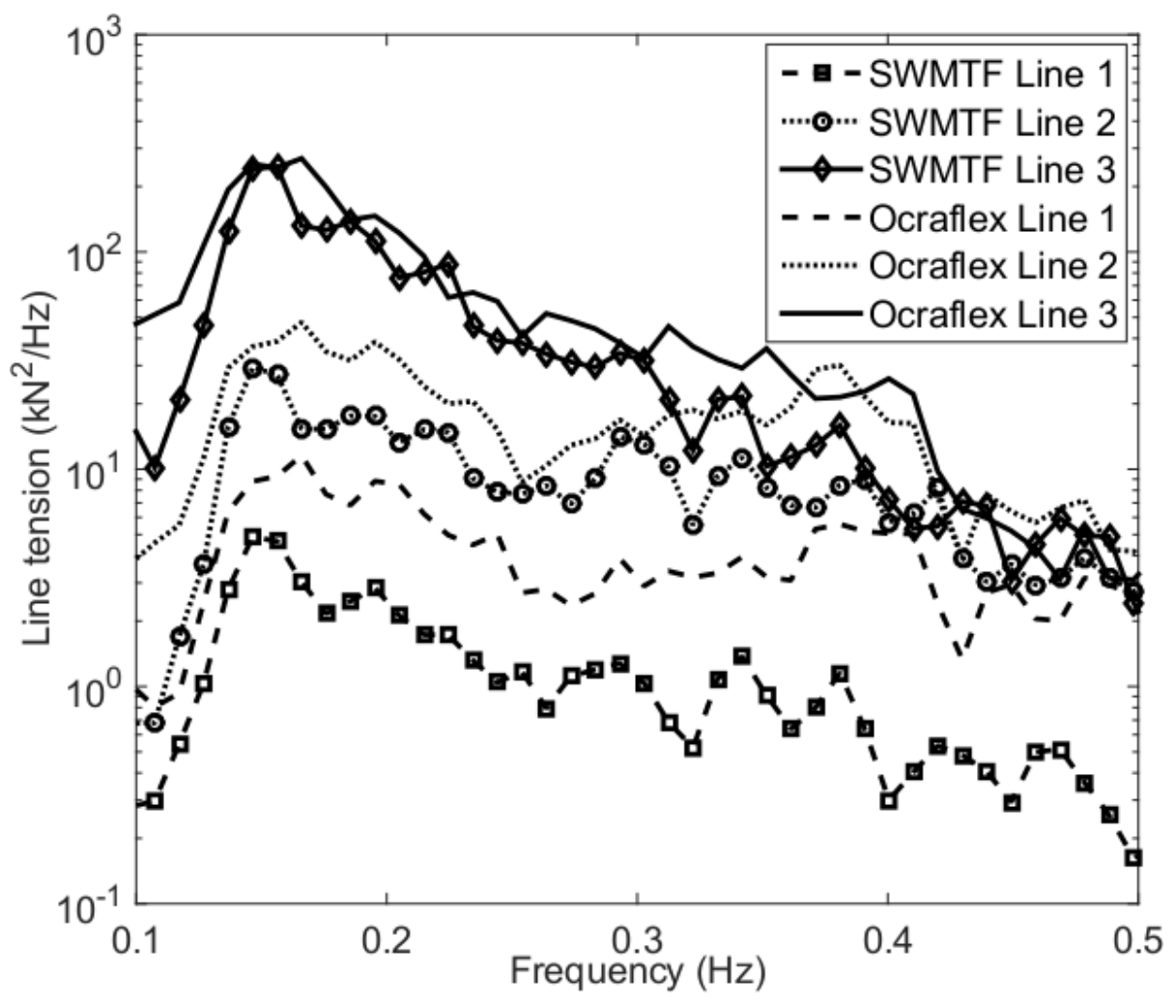

Figure 8: Comparison between Orcaflex model and SWMTF buoy line tensions for all three mooring lines

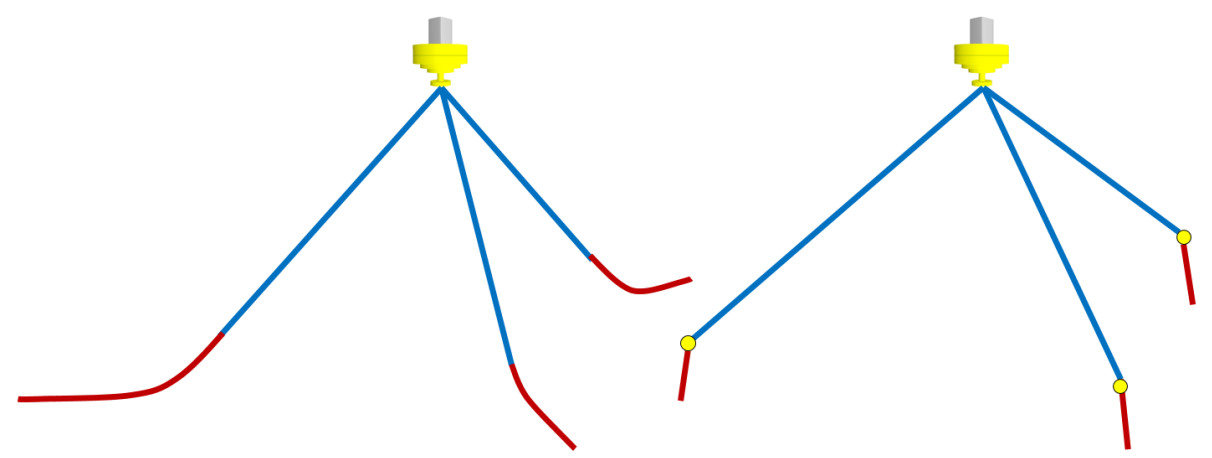

Figure 9: Catenary and taut moored system arrangements used in the dynamic model study (not to scale). 

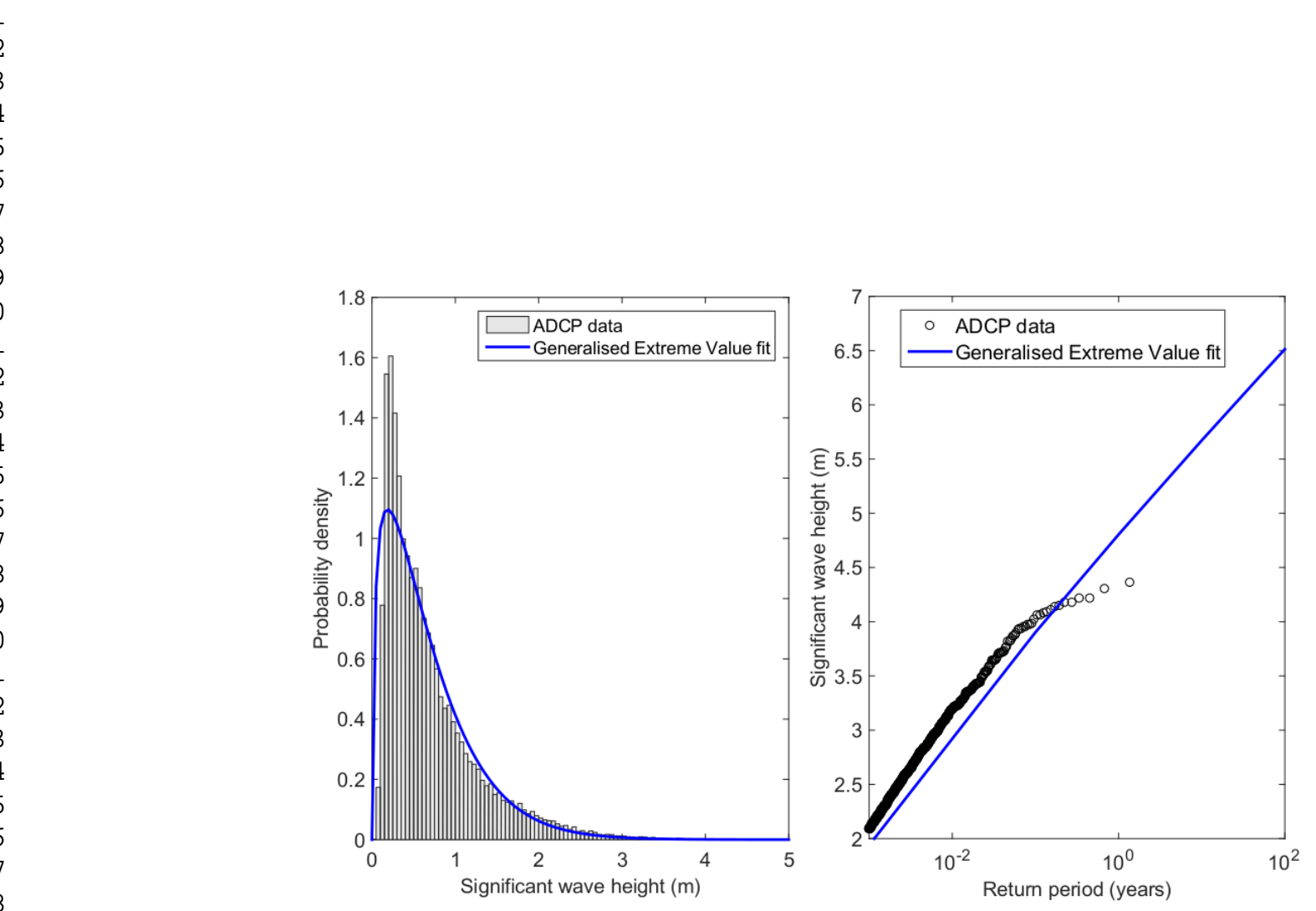

Figure 10: Extrapoloation of 100 year significant wave height at SWMTF site

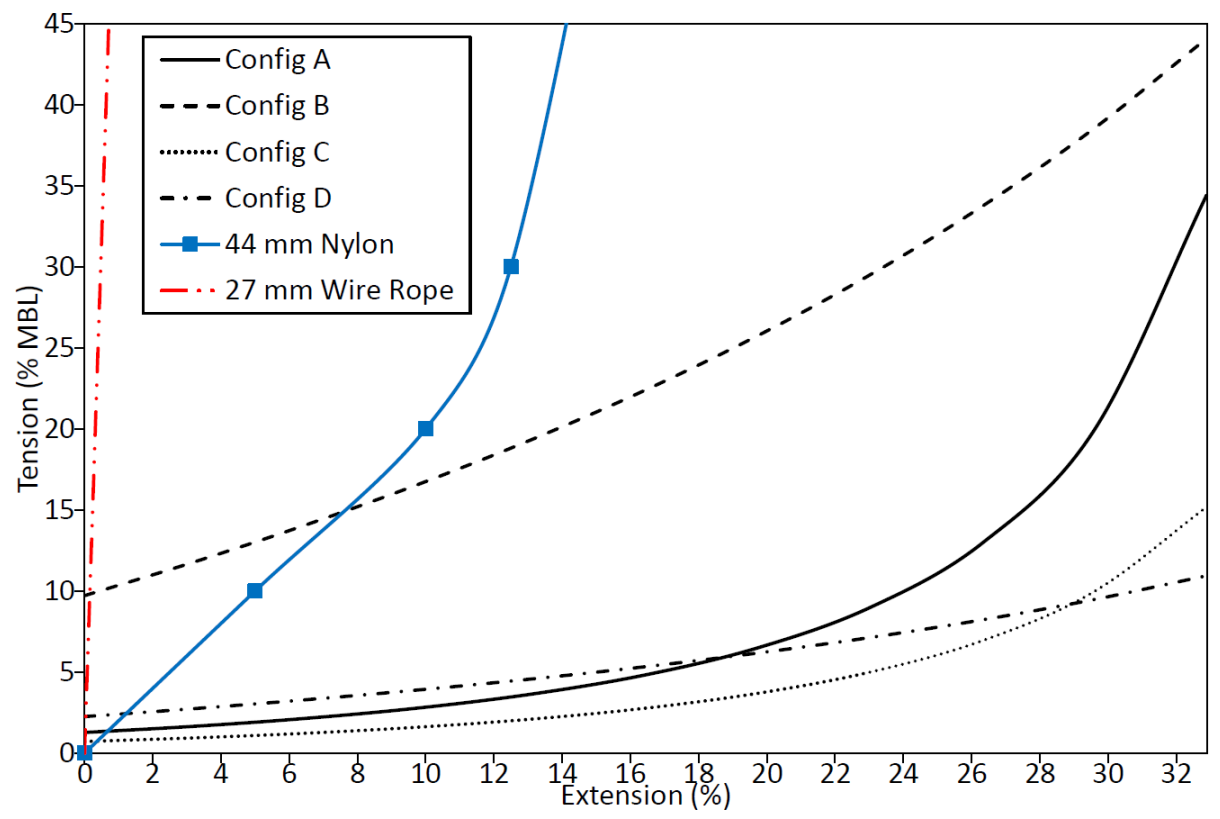

Figure 11: Load - extension curves used in the dynamic model. The tension at $0 \%$ extension was set to zero for all configurations as required by Orcaflex. 
Figure 12: Effects of mooring line composition on line tension in the extreme sea state simulations. Mooring lines presented are wire rope, nylon only and nylon and IAMS configuration

A.
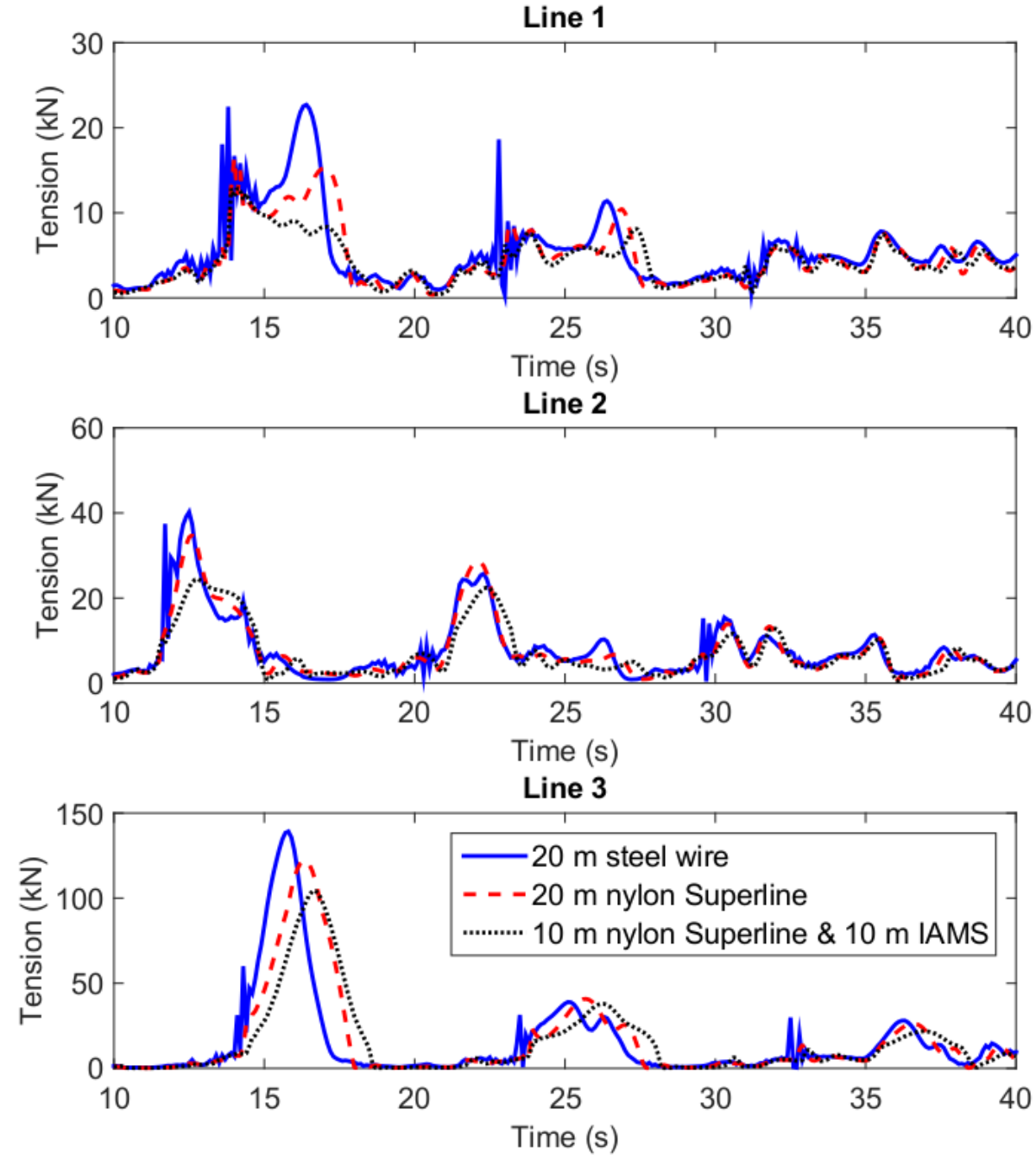
Figure 13: Effects of mooring line composition on buoy position keeping in the extreme sea state simulations. Mooring lines presented are wire rope, nylon only and nylon and IAMS configuration A. 

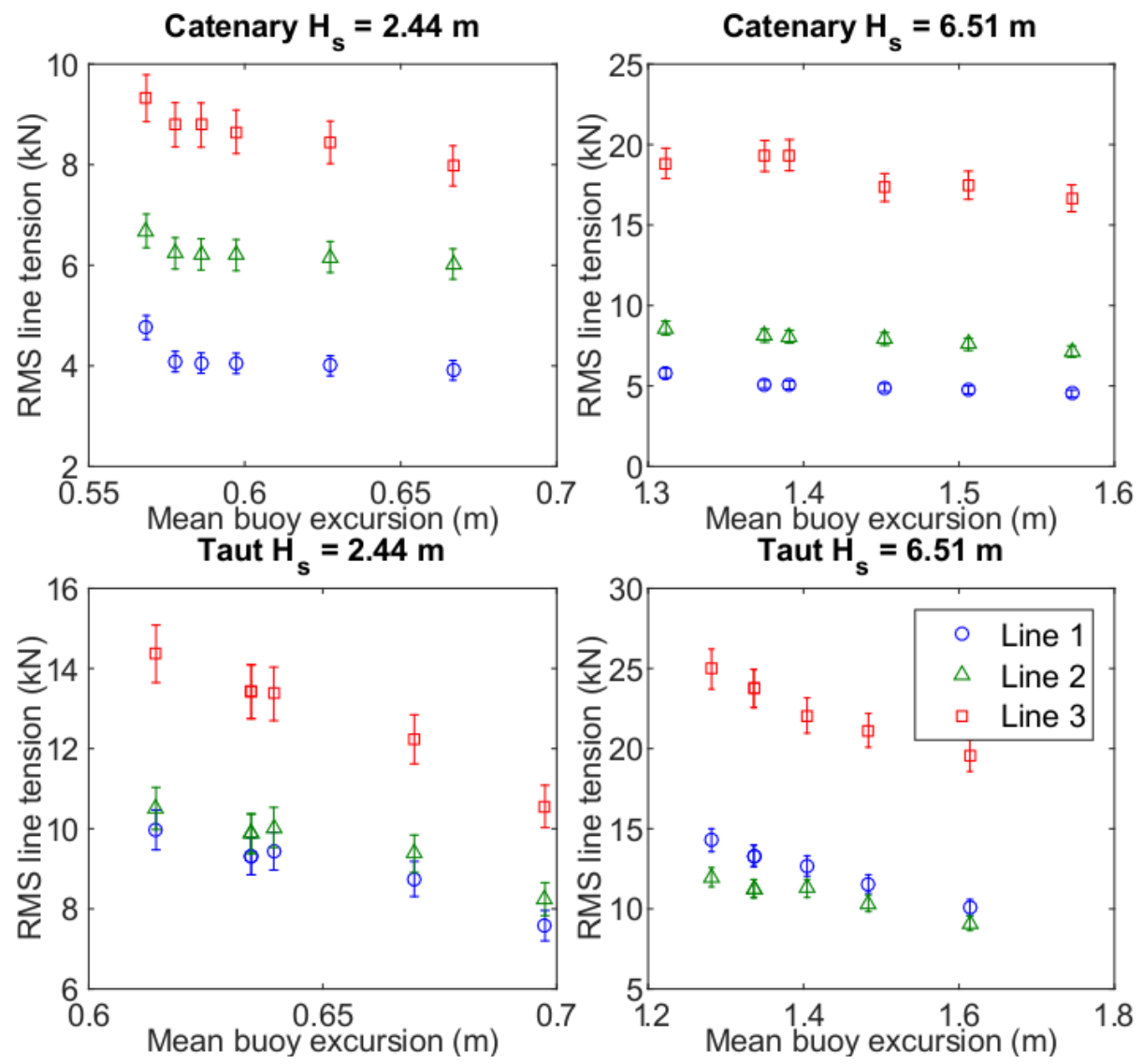

Figure 14: Root mean square line tension plotted against the mean standard deviation of the buoy excursion for all dynamic simulations. 

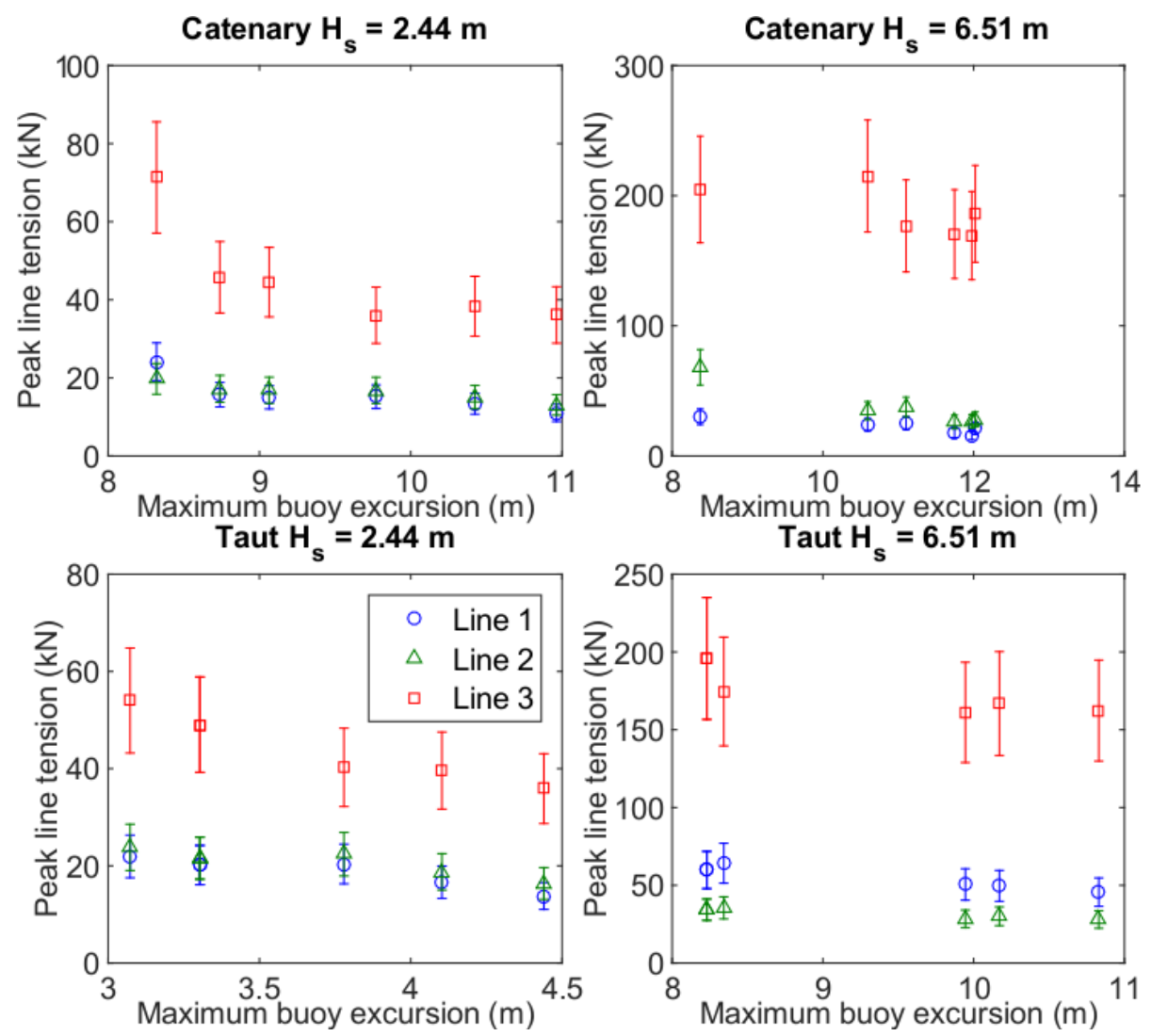

Figure 15: Peak line tension plotted against the maximum buoy excursion for all dynamic simulations. 

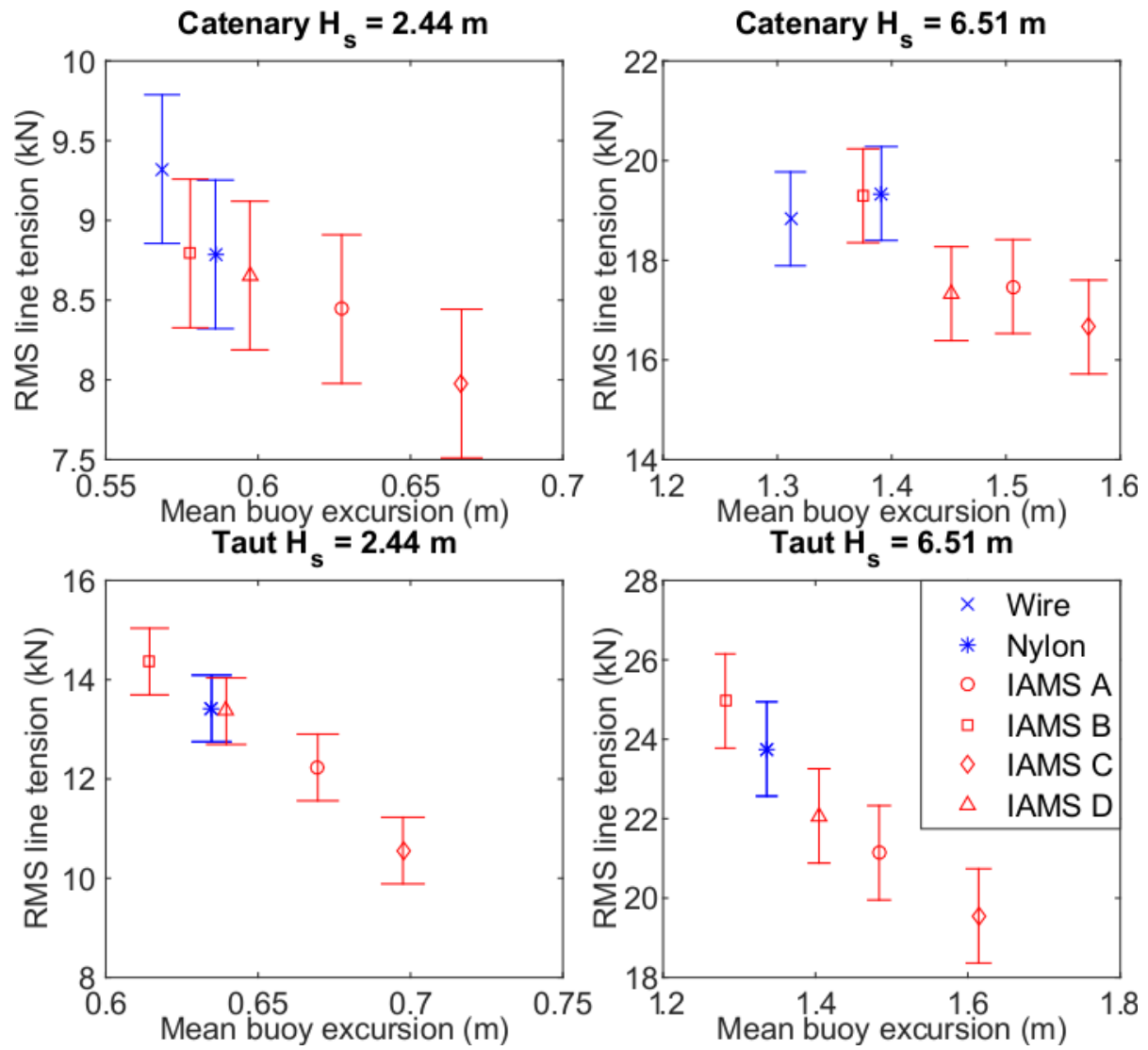

Figure 16: rms line tension in line 3 plotted against the mean standard deviation of the buoy excursion for all dynamic simulations. 

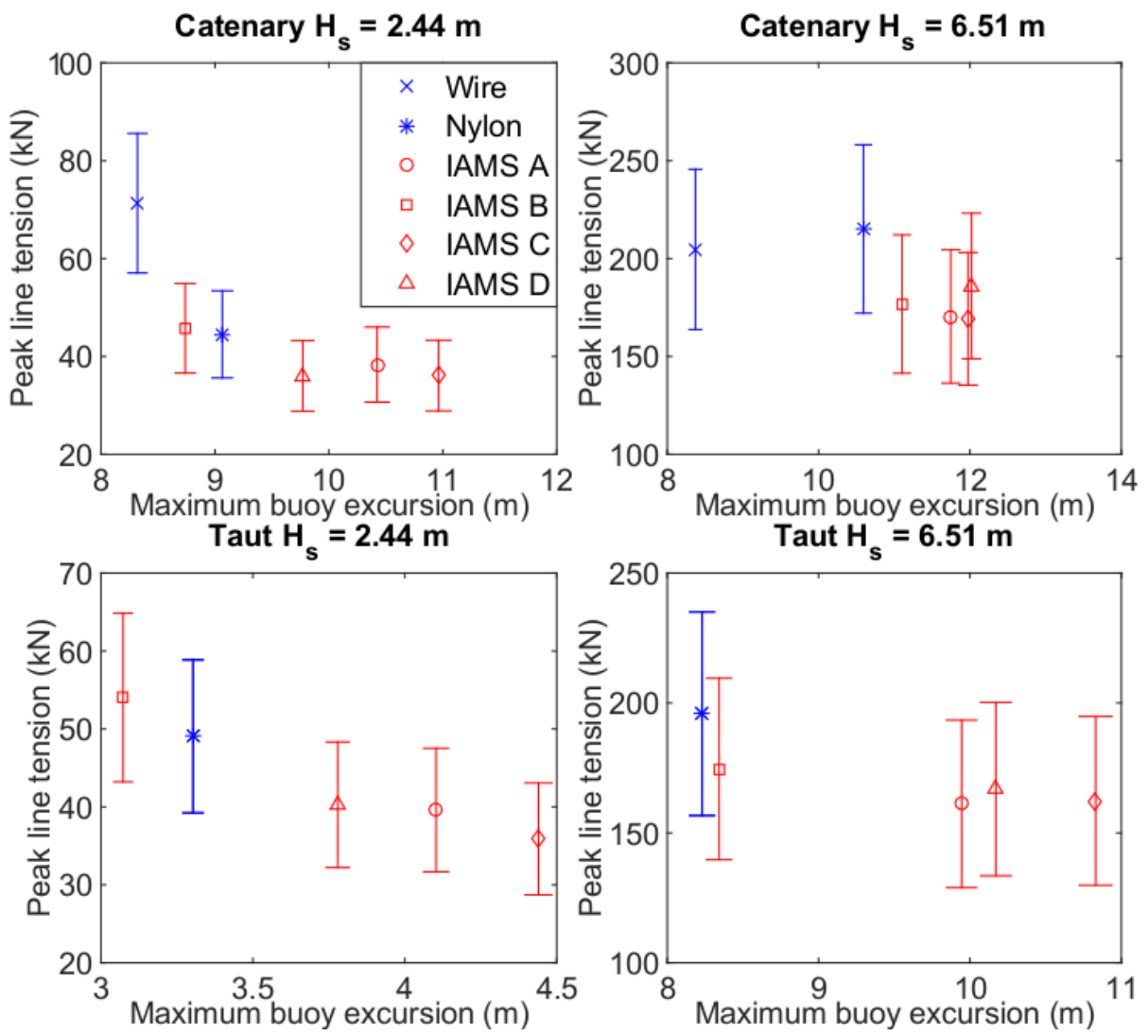

Figure 17: Peak line tension in line 3 plotted against the maximum buoy excursion for all dynamic simulations. 
LaTeX Source Files
Click here to download LaTeX Source Files: latex_source_files. $7 z$

LaTeX Source Files
Click here to download LaTeX Source Files: latex_source_files.7z Click here to download LaTeX Source Files: latex source files.7z

$\sqrt{2}$

(20) 